\title{
Life cycle assessment and feasibility analysis of a combined chemical looping combustion and Power-to-Methane system for $\mathrm{CO}_{2}$ capture and utilization
}

\author{
Bareschino, P..$^{1, *}$, Mancusi, E. ${ }^{1}$, Urciuolo, M. ${ }^{2}$, Paulillo, A. ${ }^{3,4}$, Chirone, R. ${ }^{3}$, Pepe, F. ${ }^{1}$
}

${ }^{1}$ Dipartimento di Ingegneria - Università degli Studi del Sannio,

P.zza Roma 21, 82100 Benevento - Italy

${ }^{2}$ Istituto di Ricerche sulla Combustione - Consiglio Nazionale delle Ricerche, P.le V. Tecchio 80, 80125 Napoli - Italy

${ }^{3}$ eLoop s.r.1.

V.le A. Gramsci 17/B, 80122 Napoli - Italy

${ }^{4}$ Department of Chemical Engineering - University College London, Torrington Place, WC1 E7JE, London - United Kingdom. 


\section{Abstract}

The ability to store effectively excess of electrical energy from peaks of production is key to the development of renewable energies. Power-To-Gas, and specifically Power-To-Methane represents one of the most promising option. This works presents an innovative process layout that integrates Chemical Looping Combustion of solid fuels and a Power-toMethane system. The core of the proposed layout is a multiple interconnected fluidized bed system (MFB) equipped with a two-stage fuel reactor (t-FR). Performances of the system were evaluated by considering a coal as fuel and $\mathrm{CuO}$ supported on zirconia as oxygen carrier. A kinetic scheme comprising both heterogeneous and homogeneous reactions occurring in the MFB was considered. The methanation unit was modelled developing a thermodynamic calculation method based on minimization of the free Gibbs energy. The performance of the system was evaluated by considering that the $\mathrm{CO} / \mathrm{CO}_{2}$ stream coming from the t-FR reacts over Ni supported on alumina catalyst with a pure $\mathrm{H}_{2}$ stream generated by an array of electrolysis cells. The number of cells to be stacked in the array was evaluated by considering that a constant $\mathrm{H}_{2}$ production able to convert the whole $\mathrm{CO} / \mathrm{CO}_{2}$ stream produced by the CLC process should be attained. The environmental performance of the proposed process was quantified using the Life Cycle Assessment (LCA) methodology. The analysis shows i) that the majority originate from the production and disposal of the oxygen carrier used in the t-FR, and ii) that reusing part of the oxygen produced by the electrolysis cells improves significantly the environmental performance of the proposed process. 
Keywords: $\mathrm{CO}_{2}$ Capture and Utilization; Thermal power plants; CLC-CLOU; Methanation; Life Cycle Assessment; two-stage Fuel Reactor; Environmental performances. 


\section{Latin Letters}

$A_{k} \quad$ Total number of atomic masses, -

$a \quad$ Stoichiometric coefficient, -

$c_{p} \quad$ Specific heat, $\mathrm{J} /(\mathrm{kg} \cdot \mathrm{K})$

$D \quad$ Diameter, $\mathrm{m}$

$\hat{f}_{i} \quad$ Fugacity of species $i$, bar

$f_{i}^{\circ} \quad$ Fugacity of species $i$ at standard state, bar

$G_{\mathrm{i}} \quad$ Gibbs free energy of species $i$ in the gas mixture, J

$G_{i}^{\circ} \quad$ Gibbs free energy of species i at its standard state, J

$G_{i f}^{\circ} \quad$ Gibbs free energy of formation for species $i$ at standard state, J

$h \quad$ Height of the solids bed, $m$

$K \quad$ Constant, $\mathrm{m} \mathrm{s}$

$m \quad$ Mass, $\mathrm{kg}$

$\dot{n} \quad$ Molar flow rate, $\mathrm{mol} / \mathrm{s}$

$P \quad$ Pressure, bar

$\dot{Q} \quad$ Thermal power, W/s

$Q \quad$ Specific volumetric flow rate, $\mathrm{Nm}^{3} / \mathrm{kg}$

$r \quad$ Reaction rate, $\mathrm{mol} / \mathrm{s}$

$R \quad$ Constant, $\mathrm{J} /(\mathrm{mol} \mathrm{K})$

$S \quad$ Entropy, J/K

$T \quad$ Temperature, $\mathrm{K}$

$t \quad$ Time, $\mathrm{s}$

$U \quad$ Superficial gas velocity, $\mathrm{m} / \mathrm{s}$

$W \quad$ Solids mass flow rate, $\mathrm{kg} / \mathrm{s}$

\section{Greek Letters}

$\alpha \quad$ Constant, $\mathrm{m}^{-1} \mathrm{~s}^{-1}$

$\Delta H_{r} \quad$ Standard enthalpy, J

$\delta \quad$ Bubble fraction, -

$\varepsilon \quad$ Voidage fraction, -

$v_{i, k} \quad$ Number of atoms, -

$\rho \quad$ Density, $\mathrm{kg} / \mathrm{m}^{3}$

$\eta_{e c} \quad$ Electric energy conversion efficiency, -

\section{Acronyms}

$A E L \quad$ Alkaline Electrolysis

$A R \quad$ Air reactor

CLC Chemical Looping Combustion

$C L O U$ Chemical Looping with Oxygen Uncoupling

EF Environmental footprint

$F R \quad$ Fuel reactor

HP-PEM High-Pressure Polymer Electrolyte Membrane cells

$J R C \quad$ Joint Research Centre

$L C A \quad$ Life Cycle Assessment

$M F B \quad$ Multiple interconnected Fluidized Beds 
$M R \quad$ Methanation reactor

$O C$ Oxygen Carrier

PEM Polymer Electrolyte Membrane

$P t G \quad$ Power to Gas

PtM Power to Methane

SOEC Solid Oxide Electrolysis Cell

$t$-FR Two stage Fuel Reactor

Subscript and superscript

$B \quad$ Bed

$B B \quad$ Bottom bed

in Inlet flow

$L S \quad$ Loop seal

$L V \quad$ L-valve

$m f \quad$ Minimum fluidization

$o c \quad$ Oxygen carrier

out Outlet flow

$p \quad$ Particle

$R \quad$ Riser

$S \quad$ Solids

$S B B \quad$ Solid bottom bed

slug Slug

STB Solid top bed

$T B \quad$ Top bed

TR Transfer riser 


\section{INTRODUCTION}

The largest source of greenhouse gas emissions from human activities in the world is from burning fossil fuels for electricity and heat, contributing to over half of the total $\mathrm{CO}_{2}$ emissions in the atmosphere [1]. The recent spread of renewable energy technologies, such as onshore and offshore wind and solar photovoltaic, is a symptom of a new responsiveness to environmental issues by the energy sector. In the last decade, only in the European Union electricity production from renewable sources increased nearly fourfold, from 127 to 476 TWh per year [2]. However, the integration of large amounts of renewable energies into the existing energy grid poses significant technological difficulties that are consequence of the intrinsic variability of renewable sources [3]. Therefore, the ability to store effectively excess of electrical energy from peaks of production is key to the development and the deployment of renewable energies.

Power-to-Gas (PtG) technologies represent the most promising option for the provision of large-scale, flexible energy storage by converting electrical into chemical energy [4]. Hydrogen, which is usually the product of this conversion, can be used as a fuel or injected into the natural gas network (up to a limit volumetric percentage), but for long-term storage it is usually recommended conversion of hydrogen to more stable fuels and/or chemicals [3]. Methane represents an attractive possibility because it enables to store large amounts of energy from renewable sources for long time scales in an already existing storage system: the natural gas grid; and because it can be directly used in most of endothermic engines and all other well-established natural gas facilities. Power-to-Methane (PtM) is a two-step process that involves the production of hydrogen, typically by electrolysis of water, and its conversion to methane using either $\mathrm{CO}$ or $\mathrm{CO}_{2}$ as a source of carbon. Thus, the process can also represent a mean to mitigate carbon emissions from large fixed sources.

Absorption of carbon dioxide into liquid solvents such as alkanolamines is most widely used carbon capture technology in industrial processes (e.g. ammonia production), primarily thanks to 
1 a good compromise between the rate of $\mathrm{CO}_{2}$ capture and the cost of solvent regeneration through

$2 \mathrm{CO}_{2}$ desorption [5]. However, research is still active in the selection of alternatives to reduce both pollutant emissions and $\mathrm{CO}_{2}$ capture stage costs, which accounts for up to $80 \%$ of operating costs [4]. Chemical-looping systems are under the spotlight as more efficient and cost-effective technologies than commercially available ones. Chemical Looping is based on the cyclic exposition of a solid metal oxide - known as oxygen carrier (OC) - to two different reactive environments (i.e. two different reactors connected in a loop or two different streams alternatively fed to the same reactor), which enables selective transport of a chemical, such as oxygen or carbon dioxide, between otherwise uncoupled devices/environments [6]. Among Chemical Looping systems, Chemical Looping combustion with Oxygen Uncoupling (CLOU) is a very promising technology for solid fuels combustion with inherent $\mathrm{CO}_{2}$ sequestration.

The CLOU concept is based on two cyclic steps: in the first one, the oxygen carrier is reduced releasing gaseous oxygen for fuel oxidation, whilst in the second step the reduced oxygen carrier is re-oxidized by air. Therefore, direct contact between the fuel and the atmospheric oxygen is avoided, and flue gases are mainly composed of $\mathrm{CO}_{2}$ and $\mathrm{H}_{2} \mathrm{O}$, with the latter being easily separated by condensation. The two steps occur in two reactors (named Fuel Reactor and Air Reactor) typically arranged in a dual interconnected fluidized bed configuration. This arrangement enables recirculation of the oxygen carrier between the reactors and ensures good contact between the gaseous and solid phases. However, this arrangement also presents some criticalities that are related to the effective control of solids recirculation and to the establishment of leak-tight operation of the beds with respect to the gaseous streams; these can be mitigated by correctly selecting both design and operational variables of the plant [7] and, with respect to a successful CLC of solid fuels, by properly selecting the OC and a correct design of the fuel reactor. Oxygen carriers suitable for CLOU should obviously be able to release gaseous oxygen and this $\mathrm{O}_{2}$ release must be reversible. Therefore, only metal oxides having a proper equilibrium partial pressure of 
oxygen at CLOU typical operating temperatures $\left(800-1200{ }^{\circ} \mathrm{C}\right)$ can be used. According to [8], such metal oxide systems are generally composed of an active phase consisting of metal oxides of the transition group $\left(\mathrm{CuO} / \mathrm{Cu}_{2} \mathrm{O}, \mathrm{Mn}_{2} \mathrm{O}_{3} / \mathrm{Mn}_{3} \mathrm{O}_{4}\right.$, and $\left.\mathrm{Co}_{3} \mathrm{O}_{4} / \mathrm{CoO}\right)$ coupled with a support, usually alumina or zirconia. Among them, the one most suitable for the proposed application (i.e. the one with the highest oxygen transport capacity under the CLC operating conditions) is the $\mathrm{CuO} / \mathrm{Cu}_{2} \mathrm{O}$ [9].

As mentioned above, in PtM systems hydrogen is produced by electrolysis of water using the excess electrical energy. Three different electrolysis technologies are suitable to PtG: alkaline electrolysis (AEL), polymer electrolyte membranes (PEM), and solid oxide electrolysis (SOEC). AEL represent a mature technology that has low installation costs and a reasonable lifetime, and that is available for large plant sizes. However, the technology has high maintenance costs (due to the system being highly corrosive), and during transient operation the nominal load can decrease by as much as $20 \%$. Recently PEM has been emerging as an alternative to AEL because i) it does not require corrosive substances, ii) it can reach high power densities and high operating pressure (> 100 bar), and iii) it can be operated dynamically. However, PEM has high installation costs and degrades fast. SOEC represents a very promising electrolysis technology but has only been tested at laboratory scale.

Finally, in the second step of PtM, $\mathrm{H}_{2}$ and $\mathrm{CO}_{2}$ are converted into methane. Several methanation reactor designs have been proposed and investigated in the literature [10], ranging from multiple adiabatic layers fixed beds to fluidized bed reactors, in order to control the temperature rise associated to the highly exothermic Sabatier reaction so to avoid catalyst sintering while approaching the best thermodynamic condition for the process.

In this work, we propose an innovative process layout that integrates two-stage Chemical Looping Combustion of solid fuels with Oxygen Uncoupling, hydrogen production through water electrolysis by PEM, and methanation. To the best of the authors' knowledge, there is no previous 
1 work in the literature proposing the same configuration. We investigate both the technical and

2 environmental performance of the system, with specific reference to the Italian context where vast 3 amounts of electricity from renewable sources are wasted (i.e. not dispatched nor stored [11]) as a

4 consequence of the intrinsic structure of the Italian transmission grid. The technical performance

5 is assessed in terms of the thermal power generated by MFB-CLOU and methanation units, the

6 number of electrolysis cells required to produce hydrogen, the $\mathrm{CH}_{4}$ flow rate, and the energy

7 conversion efficiency. The environmental performance is evaluated using the Life Cycle 8 Assessment methodology. LCA is a widely used methodology for quantifying the environmental 9 impacts associated with products and services $[12,13]$. The holistic perspective represents the key feature of LCA: the methodology considers the whole life cycle of a product/service, from the extraction of raw materials to the management and disposal of end-of-life wastes.

\section{MATHEMATICAL MODEL}

\subsection{Hydrodynamic and kinetic model}

Fig. 1 reports the conceptual scheme of the proposed layout with details on reactive pathways, and outlet and inlet material streams. 

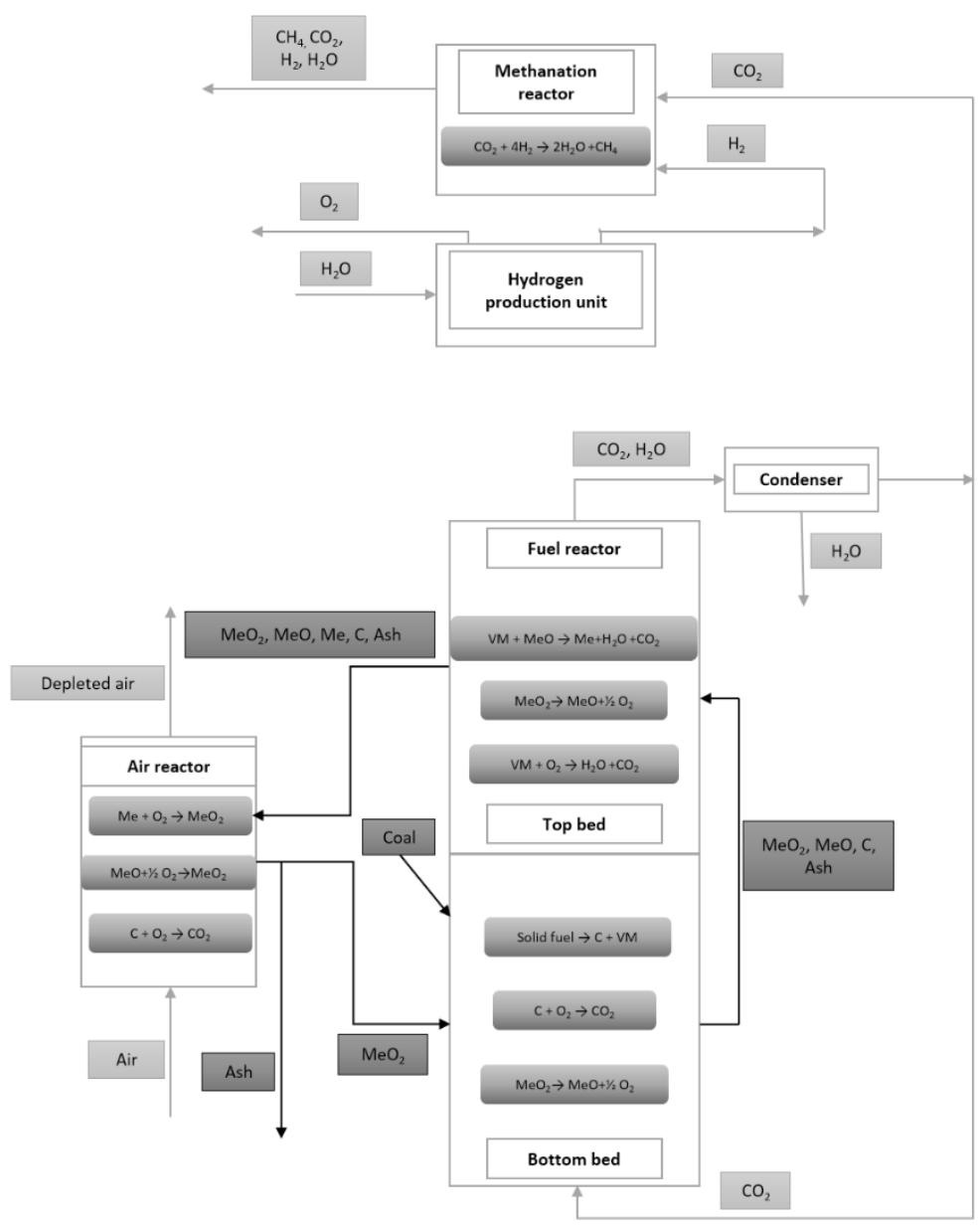

Figure 1. Conceptual scheme of the proposed process

3

The core of the layout consists of a multiple interconnected fluidized bed system equipped

with a two-stage fuel reactor, a riser used as Air Reactor, a cyclone, a L-valve return leg, and a 6 loop-seal, as sketched in Fig.2. 


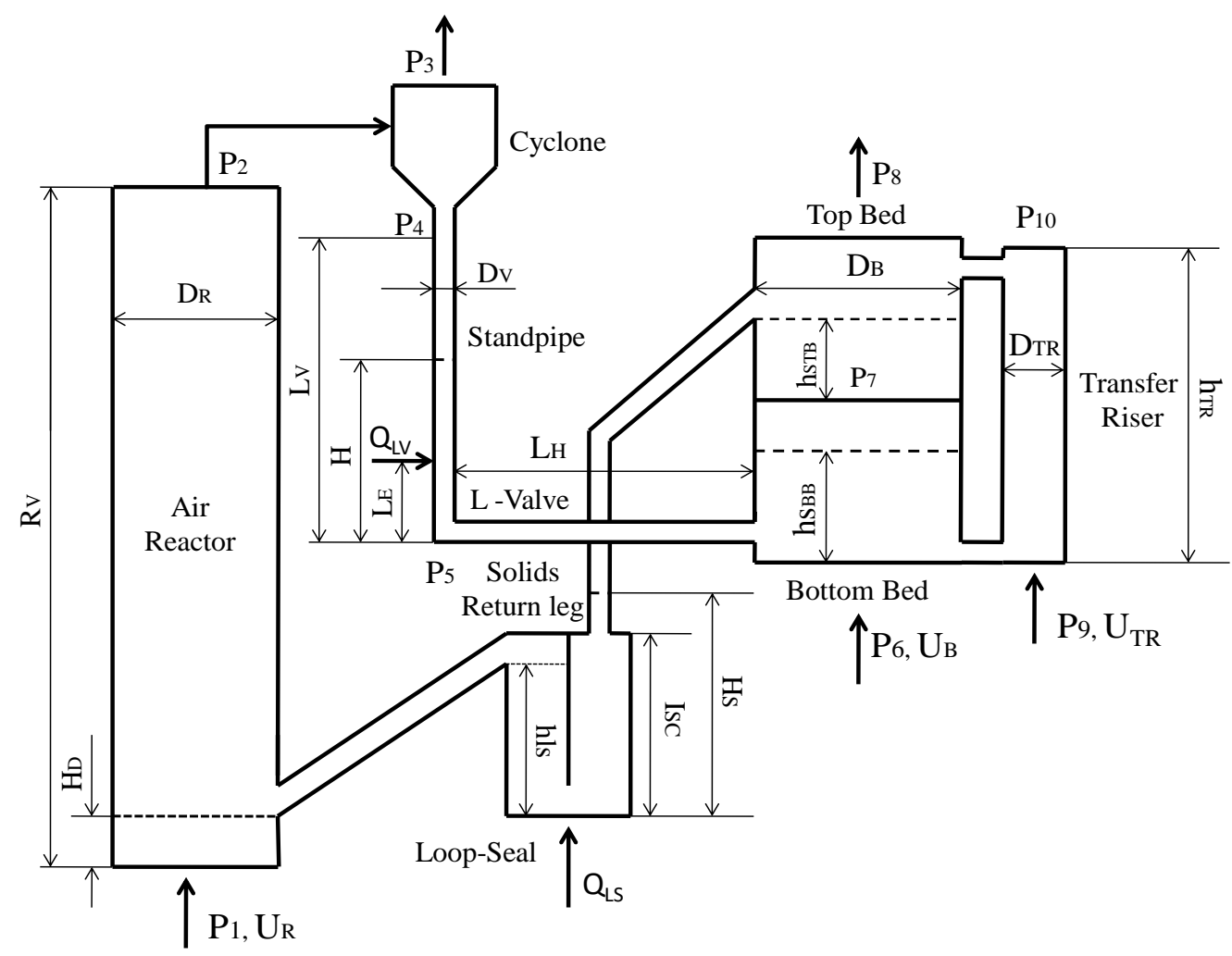

Figure 2. Schematic representation of the MFB system along with the indication of main geometric and operating variables.

beds were placed in series with respect to both gaseous and solids streams in order to overcome

the limitations of a single-stage FR. The first stage is mainly devoted to the combustion of the char exploiting oxygen release from the fully oxidized oxygen carrier (CLOU effect), while in the second stage the conversion of the volatile matter by the residual oxidative potential of the oxygen carrier took place. An internal riser connects the two stages, thus allowing the solids to move from the first stage to the other. Solids from the second stage go through the loop-seal into the AR where the oxidation capability of the $\mathrm{OC}$ is restored. A cyclone collects the regenerated OC that is sent through the L-valve to the first stage of the t-FR. At the exit of the second stage, water and fines were separated from flue gas. This latter is partly conveyed to a methanation unit in order to react with a hydrogen stream coming from an electrolysis cells array, while the remnant is recycled to the $t-F R$. 


(1)

The hydrodynamics of the MFB-CLC has been modelled as a combination of mutually interconnected blocks: risers, valves, downcomers, and a cyclone. For each block, material and momentum balance equations were written after selection of proper constitutive equations, neglecting the contribution of coal, char and ash particles to the hydrodynamics of the various components of the system. For the sake of brevity, only equations added with respect to our previous work are reported here. More details on hydrodynamic model can be found in the Supporting Information.

With respect to the t-FR, a simplified formulation of the momentum equation has been considered. It assumes that the gas pressure drop across the beds is only due to the contribution of the gravitational forces, according to:

$$
\begin{aligned}
& P_{6}-P_{7}=\left(1-\epsilon_{B}\right) \rho_{p} g h_{S B B}+\rho_{g} g\left(h_{B B}-h_{S B B}\right) \\
& P_{7}-P_{8}=\left(1-\epsilon_{B}\right) \rho_{p} g h_{S T B}+\rho_{g} g\left(h_{T B}-h_{S T B}\right)
\end{aligned}
$$

where $P_{6}, P_{7}, P_{8}, \rho_{P}, \varepsilon_{B}, h_{S B B}, h_{S T B}, h_{B B}$, and $h_{T B}$ are the pressures at the inlet and at the exit of the bottom and the top beds, the particle density, the bed voidage, the heights of the solids in the bottom and in the top bed and of the bottom and the top bed themselves, respectively. Under the assumption that elutriation is negligible, the solid mass flow rate at the outlet of t-FR is equal to that supplied from the L-valve, if the height of solid reaches the weir that connects the top bed to the loop-seal, otherwise it is zero.

The transfer riser operates in slug conditions and consequently the pressure drop along it depends both on the contribution due to the gravitational force and on the wall friction of solids flowing along the riser. Accordingly, it could be written as:

$$
P_{9}-P_{10}=\rho_{P}\left(1-\epsilon_{B}\right) g h_{T R}+\alpha W_{B 1}
$$


2 Where $P_{9}, P_{10}, h_{T R}, \alpha$, and $W_{B 1}$ are the pressures at the bottom and at the exit of the transfer riser and its height, a proportionality constant and the solid mass flow rate at the outlet of the

$$
\rho_{r}=\rho_{m f}(1-\delta)
$$

where:

$$
\delta=\frac{U_{T R}-U_{m f}}{U_{T R}-U_{m f}+U_{s l u g}}
$$

$U_{T R}, U_{m f}, U_{s l u g}$ are the gas superficial velocity in the transfer riser, the minimum fluidization velocity, and the slug velocity, respectively. This latter, according to [7], could be expressed as:

$$
U_{\text {slug }}=0.35 \sqrt{g D_{T R}}
$$

where $\mathrm{D}_{\mathrm{TR}}$ is the transfer riser diameter. The solid mass flow rate in the transfer riser is proportional to the pressure drop $P_{9}-P_{6}$; accordingly, it could be written that:

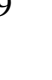

$$
W_{B 1}=K\left(P_{9}-P_{6}\right)
$$

Substituting (1)-(3) in (7) and considering that $P_{8}=P_{10}=P_{\mathrm{atm}}$, the latter equation can be rearranged as: 


$$
W_{B 1}=\frac{K}{1+\alpha K} g \rho_{m f}\left(\delta h_{T R}-h_{T R}+h_{S B B}+h_{S T B}\right)
$$

In order to make the system well-conditioned, the following global momentum and mass balances equation was written:

6

$$
\left\{\begin{array}{c}
\left(P_{3}-P_{4}\right)+\left(P_{4}-P_{5}\right)+\left(P_{5}-P_{6}\right)+\left(P_{6}-P_{7}\right)+\left(P_{7}-P_{8}\right)=0 \\
\left(P_{7}-P_{8}\right)+\left(P_{7}-P_{6}\right)+\left(P_{6}-P_{9}\right)+\left(P_{9}-P_{10}\right)=0 \\
\left(P_{8}-P_{1}\right)+\left(P_{1}-P_{2}\right)=0 \\
m_{i n v}=m_{R}+m_{L V}+m_{B B}+m_{T B}+m_{T R}+m_{L S}
\end{array}\right.
$$

where $m_{i n v}, m_{R}, m_{L V}, m_{B B}, m_{T B}, m_{T R}$, and $m_{L S}$ are the solid inventory, the mass of solids in the riser, in the L-valve, in the bottom and in the top beds, in the transfer riser, and in the loop-seal, respectively.

The transient behaviour of the system was modelled by considering the following set of ODEs and associated initial conditions:

$$
\left\{\begin{array}{c}
\frac{d m_{L V}}{d t}=W_{R}-W_{S} ; m_{L V}(0)=m_{L V 0} \\
\frac{d m_{R}}{d t}=W_{L S}-W_{R} ; m_{R}(0)=m_{R 0} \\
\frac{d m_{L S}}{d t}=W_{B 2}-W_{L S} ; m_{L S}(0)=m_{L S 0} \\
\frac{d m_{B B}}{d t}=W_{S}-W_{B 1} ; m_{B B}(0)=m_{B B 0} \\
\frac{d m_{T R}}{d t}=W_{B 1}-W_{B 2} ; m_{T R}(0)=m_{T R 0}
\end{array}\right.
$$
gas composition and flow rate, and power production. A combination of mutually interconnected blocks (risers, valves, downcomers, and a cyclone) was used to represent the unit. 
The gas-solid heterogeneous reactions taking place in the fluidized beds and the gas-phase homogeneous reactions occurring in the freeboard of fuel reactors implemented in the model were:

$$
\begin{aligned}
& \mathrm{r}_{1}: \mathrm{C}+\mathrm{CO}_{2} \rightarrow 2 \mathrm{CO} \\
& \mathrm{r}_{2}: \mathrm{CuO}+1 / 2 \mathrm{CO} \rightarrow 1 / 2 \mathrm{Cu}_{2} \mathrm{O}+1 / 2 \mathrm{CO}_{2} \\
& \mathrm{r}_{3}: \mathrm{Cu}_{2} \mathrm{O}+\mathrm{CO} \rightarrow 2 \mathrm{Cu}+\mathrm{CO}_{2} \\
& \mathrm{r}_{4}: \mathrm{CuO} \rightarrow 1 / 2 \mathrm{Cu}_{2} \mathrm{O}+1 / \mathrm{O}_{2} \\
& \mathrm{r}_{5}: \mathrm{CO}+1 / 2 \mathrm{O}_{2} \rightarrow \mathrm{CO}_{2} \\
& \mathrm{r}_{6}: \mathrm{C}+\mathrm{O}_{2} \rightarrow \mathrm{CO}_{2} \\
& \mathrm{r}_{7}: \mathrm{C}+\mathrm{H}_{2} \mathrm{O} \rightarrow \mathrm{CO}+\mathrm{H}_{2} \\
& \mathrm{r}_{8}: \mathrm{H}_{2}+1 / 2 \mathrm{O}_{2} \rightarrow \mathrm{H}_{2} \mathrm{O} \\
& \mathrm{r}_{9}: \mathrm{CuO}+1 / 2 \mathrm{H}_{2} \rightarrow 1 / 2 \mathrm{Cu} \mathrm{O}+1 / 2 \mathrm{H}_{2} \mathrm{O} \\
& \mathrm{r}_{10}: \mathrm{Cu}_{2} \mathrm{O}+\mathrm{H}_{2} \rightarrow 2 \mathrm{Cu}+\mathrm{H}_{2} \mathrm{O} \\
& \mathrm{r}_{11}: \mathrm{CuO}+1 / 4 \mathrm{CH}_{4} \rightarrow \mathrm{Cu}+1 / 4 \mathrm{CO}_{2}+1 / 2 \mathrm{H}_{2} \mathrm{O} \\
& \mathrm{r}_{12}: \mathrm{CH}_{4}+2 \mathrm{O}_{2} \rightarrow \mathrm{CO}_{2}+2 \mathrm{H}_{2} \mathrm{O} \\
& \mathrm{r}_{13}: 2 \mathrm{Cu}+\mathrm{O}_{2} \rightarrow 2 \mathrm{CuO} \\
& \mathrm{r}_{14}: \mathrm{Cu}_{2} \mathrm{O}+1 / 2 \mathrm{O}_{2} \rightarrow 2 \mathrm{CuO}
\end{aligned}
$$

Reactions 11-22 were considered to occur in the fuel reactor, whereas reactions 16, 23 and 24 apply to the air reactor. The whole set of heterogeneous and homogeneous reactions could be classified into three different categories: reactions involving carbon $(11,16,17)$, reactions involving the oxygen carrier (12-14, 19-21, 23, 24), and reactions of the volatiles $(15,18,22)$. More details on the adopted reaction kinetics can be found in in Supporting Information. 
7

$$
6 \quad \sum \dot{n}_{i}^{\text {in }}-\sum \dot{n}_{i}^{\text {out }}+\sum\left(a_{i, j} \cdot r_{j}\right)=0
$$
coefficient $a_{i, j}$. temperature, were expressed as:

Model equations consist of mass and energy balances on reagents and products. Mass balance equations, specialized to model the dense phase for both the bottom and the top bed, were referred or to single elements (i.e. $\mathrm{C}, \mathrm{H}, \mathrm{O}, \mathrm{Cu}$ ) or to specific compounds (i.e. $\mathrm{CO}_{2}$, char, $\mathrm{CH}_{4}, \mathrm{H}_{2} \mathrm{O}$ ) assuming the following general form:

where $\dot{n}_{i}^{\text {in }}$ and $\dot{n}_{i}^{\text {out }}$ represent respectively the $i^{\text {th }}$ species inlet and the outlet molar flow rate and $r_{j}$ denotes the kinetic term of the $j^{\text {th }}$ reaction involving the $i^{\text {th }}$ species by the stoichiometric

Energy balance equations, used to calculate the thermal power at the chosen operating

$$
\dot{Q}=\sum \dot{n}_{i}^{\text {in }} \cdot c_{p, i} \cdot\left(T^{0}-T_{i}^{\text {in }}\right)+\sum \dot{n}_{i}^{\text {out }} \cdot c_{p, i} \cdot\left(T_{i}^{\text {out }}-T^{0}\right)+\sum\left(-\Delta H_{r_{j}}^{0}\right) \cdot r_{j}
$$

where $c_{p, i}$ is the specific heat capacity and $\Delta H_{r_{j}}^{0}$ is the standard enthalpy of reaction of the $i^{t h}$ species, while $\dot{Q}$ is the thermal power. The specialized set of equations for each chemical species is reported in Supporting Information.

Given proximate and ultimate analysis of the fuel, operating pressure and temperature of both the Fuel and Air reactors, the outputs of the mathematical model are the total thermal power $(P, T, T h)$ - negative if generated and positive if required - to carry out isothermally the CLC, the composition and flow rate of flue gas, the required oxygen carrier mass flow rate $\left(m_{o c}\right)$, and the fluidizing gas flow rate to the Air reactor $\left(m_{\text {air }}\right)$. 
The methanation reactor (MR) has been modelled considering that $\mathrm{CO}_{2}$ reacts with $\mathrm{H}_{2}$ over $\mathrm{Ni}$ supported on alumina catalyst under equilibrium conditions and developing a thermodynamic calculation method based on the minimization of the free Gibbs energy. Such a method does not rely on the actual reactor type, thus greatly reducing the computational effort, and is based on the principle that the system total Gibbs energy, accounting for condensed and non-reacting species too, reaches its minimum value at chemical equilibrium. Accordingly, if all the species, both reactants and products, in a reactive system are known, the concentration values at equilibrium can be evaluated by using a general mathematical technique even if the kinetic pathway is unknown. In the case of methanation processes, although reactions pathway is well known (see, for instance, [15]), the mathematical problem of finding the equilibrium composition can be reformulated as the search for the minimum of the total Gibbs energy, neglecting the kinetic description of the process. The total Gibbs energy is given by:

$$
\left(G^{t}\right)_{T, P}=g\left(n_{1}, n_{2}, n_{3}, \ldots, n_{N}\right)=\sum_{i=1}^{N} n_{i} G_{i}^{\circ}+R T \sum_{i=1}^{N} \ln \left(\frac{\widehat{f}_{l}}{f_{i}^{0}}\right)
$$

The problem is to find the set $n_{i}$ which minimizes $G^{t}$ for given values of pressure and temperature, subject to the constraints of the material balances. The material balance on each element $k$ may be written assuming that the total number of atoms of each element is constant:

$$
\sum_{i} n_{i} v_{i, k}=A_{k}
$$

In Eq. (28) $A_{k}$ is the total number of atomic masses of the $k^{\text {th }}$ element $(C, H, O)$ in the system, as determined by the initial constitution of the system; $v_{i, k}$ is the number of atoms of the $k^{\text {th }}$ 
1 element present in each molecule of chemical species $i$. The Gibbs energy for these species is

2 calculated from the Gibbs-Helmholtz relation:

$$
G=H-T S
$$

4 where:

5

$$
\begin{gathered}
H=H_{298}+\int_{298}^{T} C_{P} d t \\
S=S_{298}+\int_{298}^{T} \frac{C_{P}}{T} d t
\end{gathered}
$$

7 The enthalpy at $298 \mathrm{~K}, H_{298}$, is set to zero by convention. The entropy, $S_{298}$, is given by its absolute value, and the heat capacity at constant pressure, $c_{p}$, is calculated as:

$$
c_{p}=A+B \cdot T+C \cdot T^{2}+D \cdot T^{3}+\frac{E}{T^{2}}
$$

The coefficients of Eq. (21) are from NIST Chemistry WebBook [16]. For solid Carbon a simplified formula for $c_{p}$ has been used [17]:

$$
c_{p}=A+B \cdot T-\frac{C}{T^{2}}
$$

The hydrogen production unit was modelled as an array of high-pressure polymer electrolyte membrane cells (HP-PEM). The number of HP-PEMs to be arranged in the array was evaluated by considering that a constant hydrogen production able to stoichiometrically convert the whole $\mathrm{CO}_{2}$ stream produced by the CLC process should be attained. 
Finally, the electric energy conversion efficiency $\left(\eta_{e c}\right)$, defined as the ratio between the electric energy output and input of the system, was evaluated to assess the capability of the proposed process to be used as an energy storage system, according to:

$$
\eta_{\text {ec }}=\frac{Q_{\mathrm{CH}_{4}} \cdot \mathrm{LHV}_{\mathrm{CH}_{4}} \cdot \mathrm{CF} \cdot \eta_{e}}{\text { Electric energy input }}
$$

where $Q_{C H 4}$ is methane volumetric flow rate, $L H V_{C H 4}$ is methane low heating value, $C F$ is the capacity factor, i.e. the annual number of running hours, and $\eta_{\mathrm{e}}$ is thermal-to-electric conversion efficiency.

\subsection{Operating conditions}

The hydrodynamic model was solved using the commercial software package COMSOL Multiphysics ${ }^{\circledR}$. Properties of fluidization gas, bed material, key geometrical features of the components, and operating conditions of both t-FR and AR were reported in the Supporting Information, with the exception of the transfer riser height and diameter $(1.93 \mathrm{~m}$ and $0.04 \mathrm{~m}$, respectively), t-FR diameter $(0.38 \mathrm{~m})$, and top- and bottom-bed height $(1 \mathrm{~m})$.

Properties of solid fuel, evaluated by means of proximate and ultimate analysis, carried out by LECO CHN 628, LECO CS 144 and LECO TG701, are reported in Table 1.

Table 1 - Properties of considered fuel

\begin{tabular}{cr}
\hline \multicolumn{2}{c}{ Proximate analysis, -} \\
\hline Moisture & 0.1 \\
Volatiles & 0.2 \\
Fixed carbon & 0.6 \\
Ash & 0.1 \\
\hline \multicolumn{2}{c}{ Ultimate analysis, - } \\
\hline $\mathrm{C}$ & 0.7 \\
$\mathrm{H}$ & 0.1 \\
$\mathrm{~N}$ & 0.0 \\
$\mathrm{~S}$ & 0.1 \\
$\mathrm{O}$ & 0.1 \\
\hline
\end{tabular}


For the MFB-CLC unit, operating pressure was set at $10^{5} \mathrm{~Pa}$ while fuel and air reactor operating temperatures were set at $1173.15 \mathrm{~K}$ and $923.15 \mathrm{~K}$, respectively.

For the methanation unit, operating pressure was varied between 1 and 50 bar while temperature was varied between $558.15 \mathrm{~K}$ and $1100 \mathrm{~K}$, the former being the activation temperature of the chosen catalyst. Under the above operating conditions, ideal gas state equation can be safely considered in the evaluation of Eq. 27; accordingly, $\hat{f}_{i}=P y_{i}, f_{i}^{\circ}=1$, and $G_{i}^{\circ}=\Delta G_{i, f}^{\circ}$.

For the evaluation of the number of HP-PEMs to be arranged in the array, data from commercially available units were considered [18]. Accordingly, a nominal $\mathrm{H}_{2}$ production flowrate of $100 \mathrm{Nm}^{3} / \mathrm{h}$ and an electric energy efficiency equal to $46.6 \mathrm{kWh} / \mathrm{kg}_{\mathrm{H} 2}$ were taken into account. It should be noted here that, according to [2,11], around $360 \mathrm{GWh}$ of windproduced electric energy were wasted (not dispatched nor stored) in Italy over the last 3 years as a consequence of the zonal structure of the Italian transmission grid that tends to cap energy flows from southern regions (where it is mainly produced) to northern ones (where most of energy consuming factories are). Due to the magnitude of this wasted electricity, it is reasonable to assume that the HP-PEMs array operates in continuous.

\subsection{Life Cycle Assessment}

The Life Cycle Assessment methodology is deployed to identify the main sources of environmental impacts (i.e. "hot-spots") associated with the innovative layout introduced above and to assess its environmental performance compared with an equivalent system of reference that delivers the same functions. The analysis is specific to the Italian context (see Section 1); this means that, where available, inventory data specific to Italy is used.

The proposed system has the twofold function of generating electricity and producing methane. Notably, we assume a 30\% efficiency in converting the thermal energy generated by the Chemical Looping Combustion (CLC) reactor to electricity. We also assume that wasted 
1 electricity from onshore wind farms is used to produce hydrogen from water. The reference

2 system for comparative purposes comprises the conventional pathways to generate electricity and to produce methane: electricity is assumed to be generated according to the Italian electricity grid mix, whilst methane is produced from conversion of natural gas. The functional unit, which in LCA represents a quantified description of the functions delivered by the system, is equal to $1 \mathrm{kWh}$ of electricity generated and $0.49 \mathrm{~kg}$ of methane produced. Fig. 3 illustrates the comparative analysis performed. The system boundary of the proposed innovative layout is divided into Foreground and Background [19]. The former is defined as the "processes whose includes all activities in their life-cycle. 


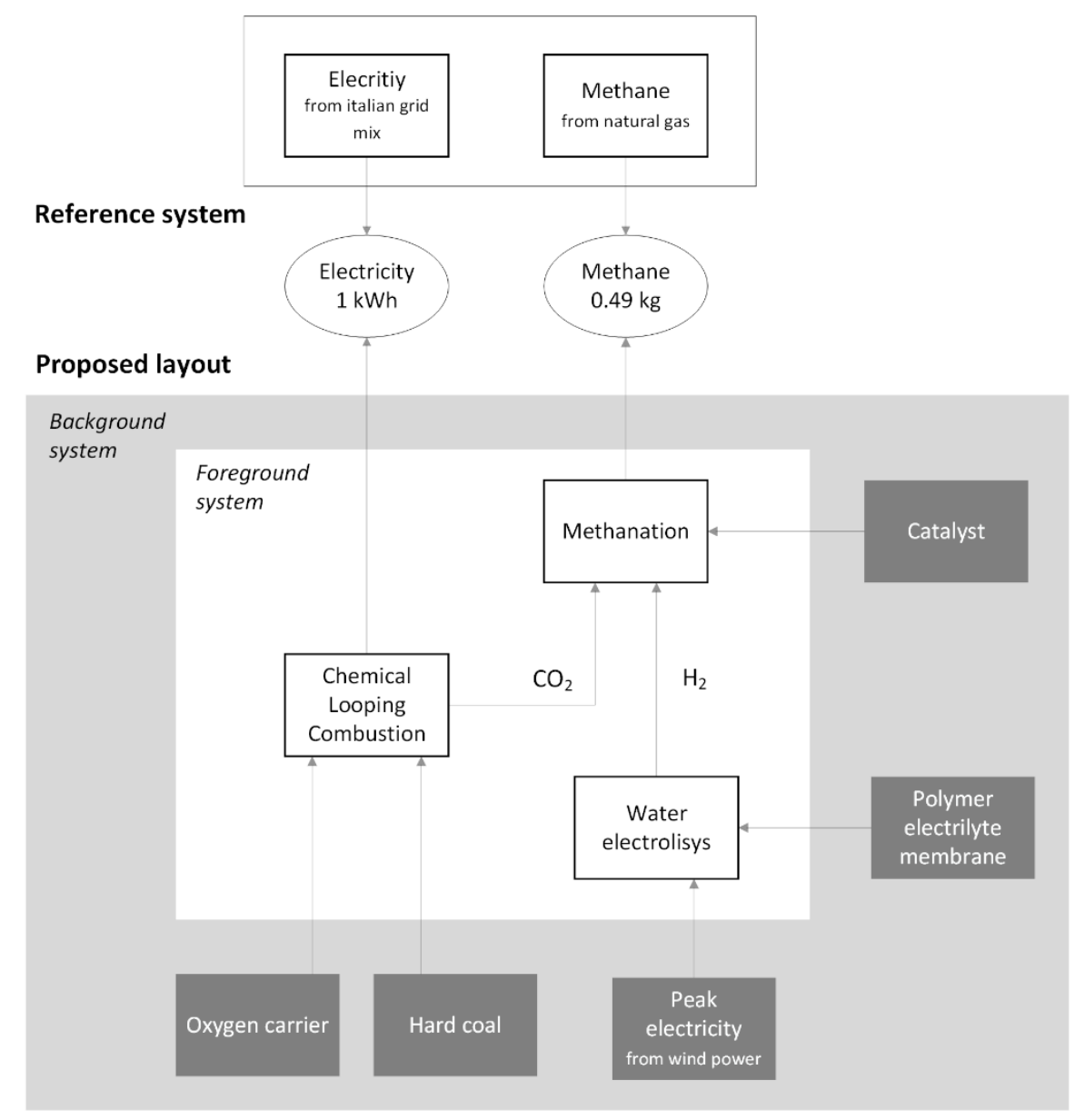

Figure 3. Simplified boundaries of the comparative analysis between the innovative process proposed in this study and the reference system. For simplicity, the diagram does not include the construction phase of the units in the Foreground system.

The life-cycle inventory is based on the results of the mathematical model developed in this study and on literature data, and is reported in the Supporting Information. Results of the model presented in this study (Sections 2.1 and 2.2) are used to describe the operation of the CLC reactor and of the methanation unit in terms of mass and energy inputs/outputs. Data for the HP-PEM unit is based on this study and on the Ecoinvent database, version 3.5 cut-off model [20]. Data on the construction phase is obtained from Ecoinvent for the CLC reactor (note that we assume that construction of the CLC reactor for electricity production is equivalent to that of a coal power plant), on Ecoinvent and [18] for the HP-PEM cell, and on [21,22] for the methanation reactor using a nickel catalyst. The oxygen carrier is assumed to consists of $50 \%$ copper oxide and $50 \%$ zirconia; data on its production is on a laboratory scale and is based on 
1 [23]. Finally, life-cycle inventory data for the remaining activities in the Background system,

2 and for the conventional pathway to methane production and electricity from the Italian grid mix (which primarily comprises of $28 \%$ natural gas, $15 \%$ coal, $22 \%$ hydro, $6 \%$ wind and $17 \%$ imported from other countries) are obtained from the Ecoinvent database. of the European Commission [24,25] is used for quantifying the environmental impacts. We

7 included all impact categories, but report climate change impacts only in terms of the sum of the contributions from fossil and biogenic greenhouse gases and land-use change. A description of these environmental impact categories can be found at [26]. For the comparative analysis, the environmental impacts are normalized to the reference impact per person of EU-28 using the EF 2.0 normalization factors [27].

In the article we focus on 12 impact categories, reported in Table 2, which feature normalized impacts higher than an arbitrarily set threshold of $10^{-4}$ persons equivalent for both the proposed layout and the reference system.

Table 2. Environmental impact categories analysed

\begin{tabular}{ll}
\hline IMPACT CATEGORY & METRIC \\
\hline Acidification & Mole of H+ eq. \\
Cancer human health effects & CTUh \\
Climate change & $\mathrm{kg} \mathrm{CO}$ eq. \\
Ecotoxicity freshwater & $\mathrm{CTUe}$ \\
Eutrophication freshwater & $\mathrm{kg} \mathrm{P}$ eq. \\
Eutrophication terrestrial & Mole of N eq. \\
Ionising radiations & $\mathrm{kBq}$ U235 eq. \\
Non-cancer human health effects & $\mathrm{CTUh}$ \\
Photochemical ozone formation - human health & $\mathrm{kg} \mathrm{NMVOC} \mathrm{eq.}$ \\
Resource use, energy carriers & MJ \\
Resource use, mineral and metals & $\mathrm{kg}$ Sb eq. \\
Respiratory inorganics & Deaths \\
\hline
\end{tabular}




\section{RESULTS AND DISCUSSION}

\subsection{Technical performance}

Table 3 reports, with respect to $1 \mathrm{~kg} / \mathrm{h}$ of fuel fed, the generated thermal power $(P, T, T h)$, the $\mathrm{CO}_{2}$ volumetric flow rate $\left(Q_{\mathrm{CO} 2}\right)$, the required oxygen carrier mass flow rate, and the fluidizing gas flow rate to the Air reactor.

Table 3 - MFB-CLC model outputs

\begin{tabular}{cc}
\hline$P_{, T, T h}, \mathrm{~kW} / \mathrm{s}$ & 4.3 \\
$Q_{\mathrm{CO} 2}, \mathrm{Nm}^{3} / \mathrm{s}$ & $3.710^{-4}$ \\
$m_{o c}, \mathrm{~kg} / \mathrm{s}$ & $1.010^{-2}$ \\
$Q_{a i r}, \mathrm{Nm}^{3} / \mathrm{s}$ & $3.710^{-6}$ \\
\hline
\end{tabular}

The required $\mathrm{H}_{2}: \mathrm{CO}_{2}$ ratio for the methane synthesis is $4: 1$ [8]. On the basis of the $\mathrm{CO}_{2}$ volumetric flow rate at the exit of the fuel reactor (Table 3), the hydrogen $\left(Q_{H 2}\right)$ and oxygen $\left(Q_{O 2}\right)$ volumetric flow rates and the number of electrolytic cells $(N c)$ can be consequently evaluated. Data are reported in Table 4.

Table 4 - HP-PEM model outputs

\begin{tabular}{cc}
\hline$N_{c},-$ & $5.310^{-2}$ \\
$Q_{H 2}, \mathrm{Nm}^{3} / s$ & $1.510^{-3}$ \\
$Q_{O 2}, \mathrm{Nm}^{3} / \mathrm{s}$ & $7.410^{-4}$ \\
\hline
\end{tabular}

Fig. 4 reports, as a function of the operating temperature, the gas molar fractions at the output of the methanation unit parametric with the operating pressure. The analysis of the above figure suggests that, whatever the operating pressure, in order to achieve high methane content operating temperature should be set as low as possible. A low operating temperature has furthermore the beneficial effects to avoid carbon monoxide formation and to keep hydrogen concentration as low as possible.

In principle, depending on type of catalyst, feed gas composition, and operating conditions, it should be noted that carbon deposition on supported catalyst can occur (according to the 
1 Boudouard reaction); in order to avoid this, temperature should be kept high or $\mathrm{CO}_{2}$ and/or $\mathrm{H}_{2} \mathrm{O}$

2 has to be added to the feed (e.g. [28]).

3 However, under the current assumption that $\mathrm{H}_{2}$ and $\mathrm{CO}_{2}$ are stoichiometrically fed to the methanation unit, no carbon deposition can occur. Accordingly, it could be settled that, above catalyst activation temperature, the lower the operating temperature the better in terms of methane concentration, notwithstanding the operating pressure.

With respect to the choice of the optimal operating pressure, an analysis of the same figure suggests that, for any given operating temperature, increasing the methanation unit pressure from 5 to 20 bar significantly increases both methane and water molar fraction while reduces residual hydrogen content. However, an increase in operating pressure from 20 to 50 bar does not alter appreciably gas composition as long as the operating temperature is close to catalyst activation one. above catalyst activation temperature the lower, the better; ii) with respect to the choice of the operating pressure, a "threshold" pressure value exists for any given temperature beyond which any further pressure increase does not correspond to substantial variations in both hydrogen and methane concentrations. 


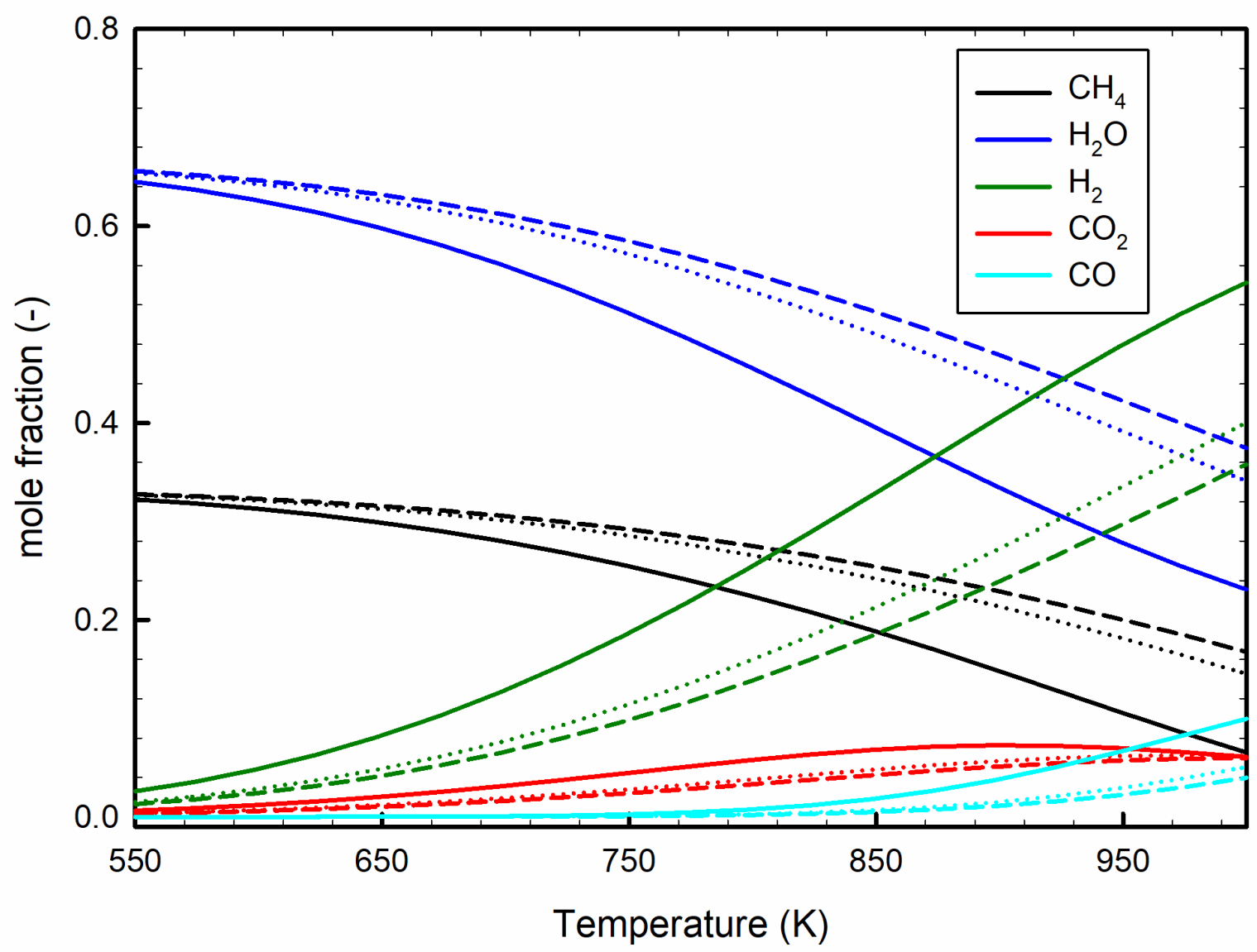

Figure 4 - Gas molar fractions at the outlet of methanation unit as a function of the operating temperature at an operating pressure of 5 bar (solid lines), 20 bar (dotted lines), and 30 bar (dashed lines).

1 From the above cited figure, it can additionally be seen that water concentration is always higher

2 than methane one, so drying of the methanation output stream is mandatory. After water removal,

3 the concentration of methane boosts together with the residual concentrations of both hydrogen

4 and carbon dioxide. In order to improve process methane yield, a second methanation unit is

5 therefore considered in series with the first one. Table 5 reports the carbon dioxide $\left(Q_{\mathrm{CO} 2}\right)$,

6 hydrogen, and methane $\left(Q_{C H 4}\right)$ volumetric flow rates at the output of this second unit when the

7 operating pressure is set at 20 bar and the operating temperature varies in a narrow interval above

8 the catalyst activation one. An almost complete conversion of $\mathrm{CO}_{2}$ and $\mathrm{H}_{2}$ is obtained, whatever

9 the operating temperature considered. More specifically, the conversion degrees are $99.2 \%$ and

$1098.5 \%$ for 558 and $623 \mathrm{~K}$, respectively. With respect to methane concentration, in both cases a 
1 value higher than the required one for its injection into the natural gas grid (i.e. $>95 \%$ ) is

2 achieved.

3

\begin{tabular}{ccc}
\multicolumn{4}{c}{ Table 5-Methanation units model outputs } \\
\hline \multicolumn{1}{c}{$T, \mathrm{~K}$} & 558 & 623 \\
& & \\
\hline$Q_{\mathrm{CO} 2} 10^{8}, \mathrm{Nm}^{3} / \mathrm{kg}$ & 7.4 & 9.8 \\
$Q_{\mathrm{H} 2} 10^{6}, \mathrm{Nm}^{3} / \mathrm{kg}$ & 7.0 & 9.8 \\
$Q_{\mathrm{CH} 4} 10^{4}, \mathrm{Nm}^{3} / \mathrm{kg}$ & 3.3 & 3.3 \\
\hline
\end{tabular}

5

6 The electric energy conversion efficiency evaluated for the proposed process is $\sim 16 \%$, 7 regardless of the methanation unit operating temperature and pressure.

8

9

\subsection{Environmental performance}

Numerical results of the LCA study are included in the Supporting Information. Fig. 5 reports the comparative analysis in terms of normalized impacts between the proposed layout and the reference systems. 


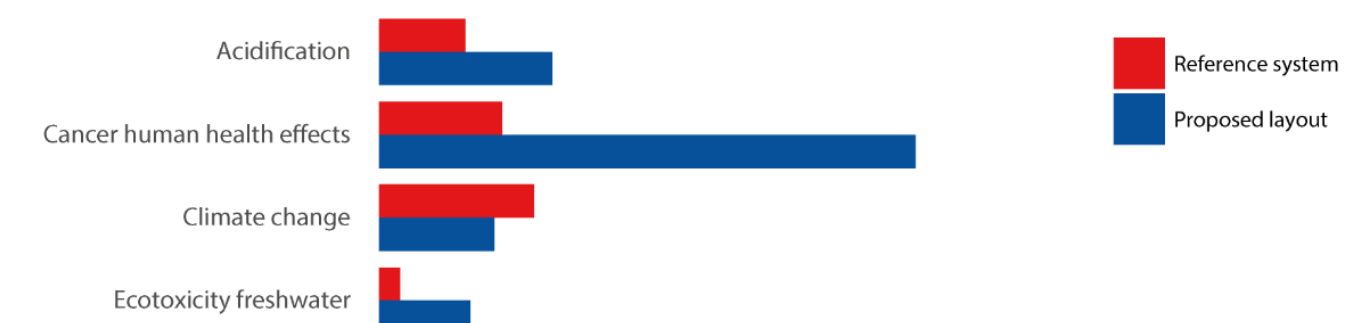

Eutrophication freshwater

Eutrophication terrestrial

lonising radiations

Non-cancer human heath effects

Photochemical ozone formation - human health

Resource use, energy carriers

Resource use, minerals and metals

Respiratory inorganics

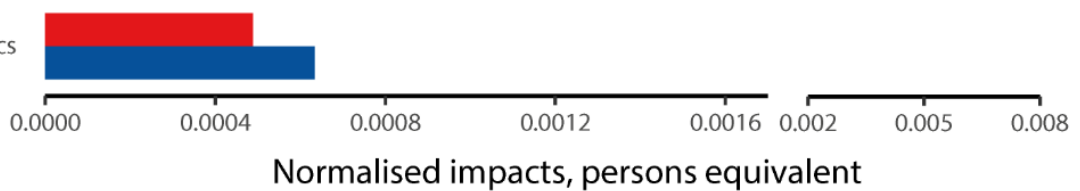

The chart shows that the proposed process outperforms the reference system only with respect to the categories climate change and ionizing radiations, whilst it has a similar performance in the category terrestrial eutrophication. Specifically, the proposed layout delivers a reduction of about $25 \%$ of impacts due to greenhouse gases, and about $40 \%$ of impacts on humans due to radionuclides. However, the proposed process yields significant increases in other impact categories, as high as $\sim 28$ times for non-cancer human health effects and $\sim 22$ times for the depletion of minerals and metals; the impact in both categories is attributable to oxygen carrier, specifically to its disposal for the former and to its production for the latter as explained below. The normalization procedure also reveals that carcinogenic and non-carcinogenic toxic impacts (which originate from activities in the background system), freshwater eutrophication and depletion of mineral and metals represent the most critical impact categories for the proposed process. 
Fig. 6 reports the hot-spot analysis for the process developed in this article. It is evident

2 from the chart that the largest portion of the environmental impacts originate from the CLC unit, with contributions ranging from $90 \%$ in the category "ionizing radiations" and up to $\sim 100 \%$ in the category "freshwater eutrophication".

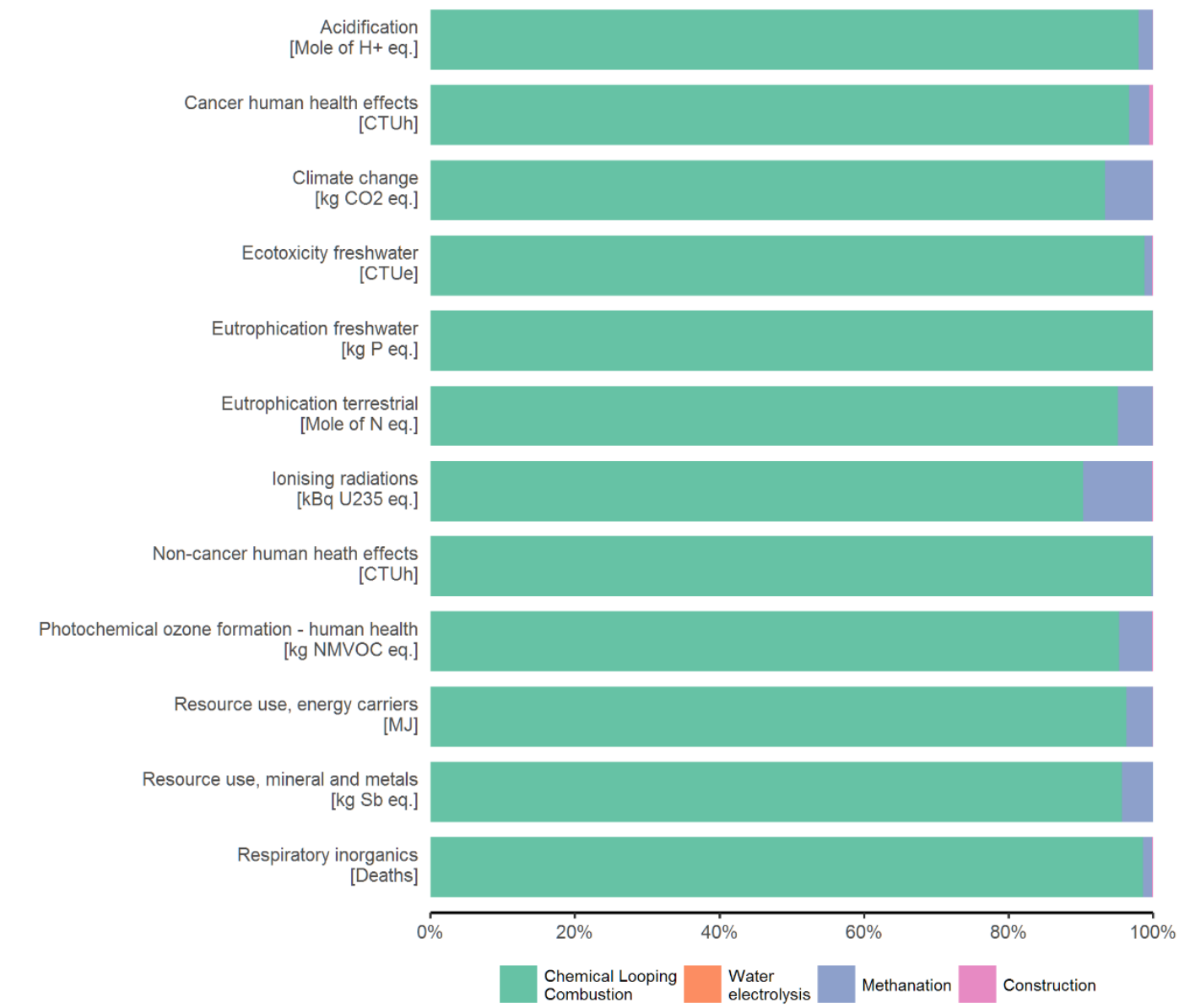
Figure 6 - Hot-spot analysis of the proposed process layout. The label "Construction" includes construction of all
units

Interestingly, the results from the LCA analysis reveal that the impacts of the CLC unit are primarily attributable to the production of the oxygen carrier (OC), and, for carcinogenic and non-carcinogenic human health impacts, to its disposal (see Fig. S2 in the Supporting Information). Similar results are found by [23]. The amount of OC used up by the CLC reactor includes an initial loading plus additional amounts to make up for the loss of the carrier due to elutriation ( $\sim 0.5 \%$ of the OC mass flow rate within the CLC unit); the OC lost by elutriation is 
1 assumed to be captured by filters and treated as hazardous waste, which, according to

2 Ecoinvent, entails incineration and landfilling. The environmental impacts associated with the production of the oxygen carrier are approximately equally shared between production of copper oxide and zirconium oxide with the exception of the category climate change, where energy consumption represent the dominant source of impacts.

The proposed layout represents therefore a valid solution only with respect to climate change and ionizing radiations impacts; the performance in the remaining categories is poor when compared to the conventional technologies. The results of the LCA analysis suggest that efforts to improve its environmental performance should be primarily focused on the oxygen carrier.

An effective strategy could be to reduce the amount of oxygen carrier used by the CLC system by directly feeding part or all of the oxygen produced in the HP-PEM unit to the t-FR unit. This in fact reduces the amount of both the OC needed to carry out CLC (since part of the fuel directly reacts with gaseous oxygen) and the spent OC to be treated. Under the current assumption that the amount of hydrogen produced in the HP-PEM units is that needed to stoichiometrically convert the whole $\mathrm{CO}_{2}$ stream fed to the methanation unit, double the oxygen required to fully oxidize all of the carbon content of the fuel is actually released at the same time. Fig. 7 extends the comparative analysis reported in Fig. 5 to three additional scenarios where increasing fractions (arbitrarily set to $11 \%, 22 \%$, and $33 \%$ ) of the oxygen produced in PEM units are available to be used in the t-FR, resulting in increasing reductions of the amount of oxygen carrier needed (namely, about $30 \%, 60 \%$, and $90 \%$ ). 


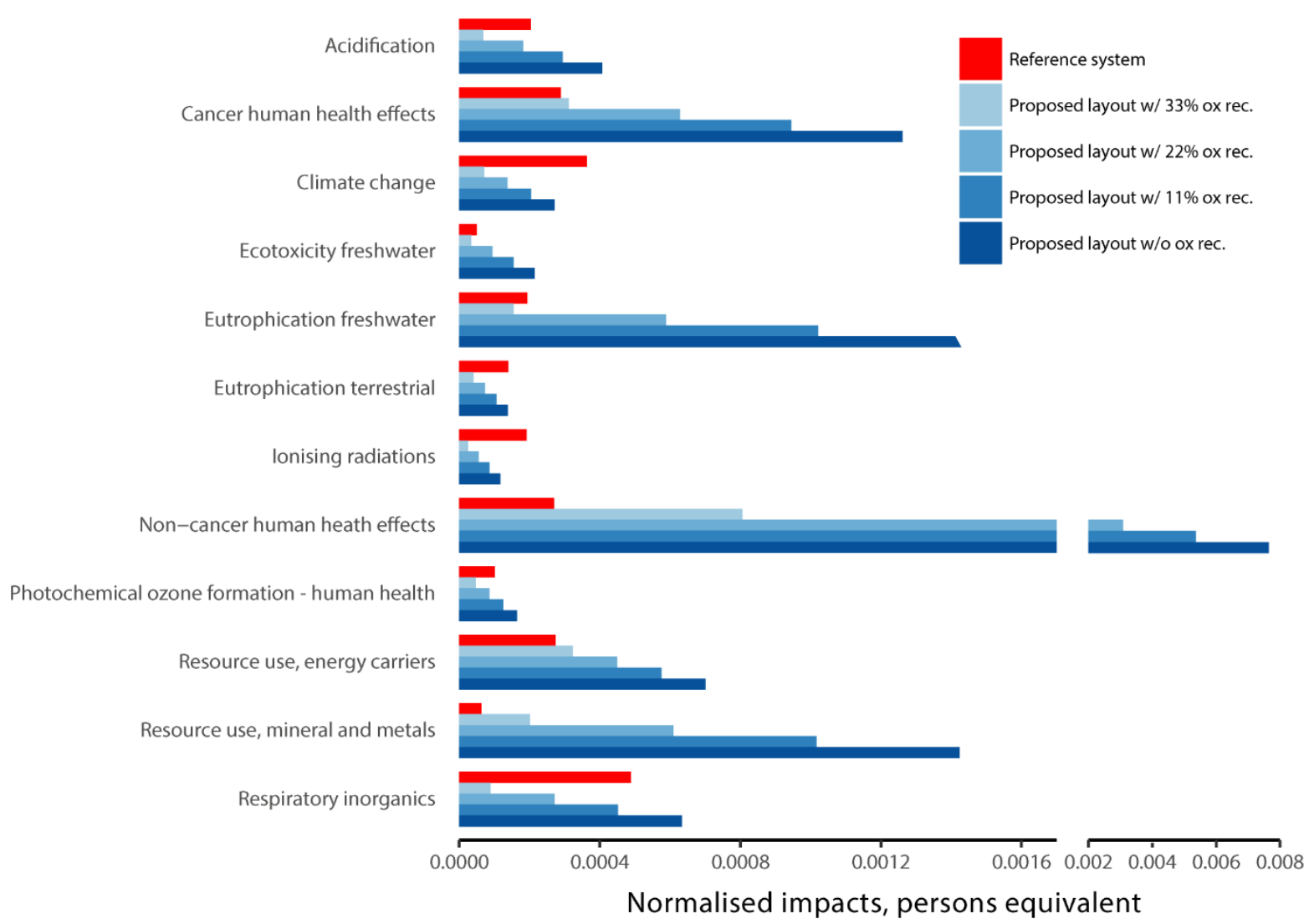

Figure 7 - Normalised environmental impacts of the reference system, the proposed process, and scenarios for PEMproduced oxygen exploitation.

The chart shows that exploitation of the HP-PEM produced oxygen exploitation can yield

substantial improvements in the environmental performances of the proposed layout. At $11 \%$, the proposed system performs better than the reference one not only with respect to climate change and ionizing radiations impacts (as in the case without oxygen feeding, see Fig. 5), but also with respect to the category respiratory inorganics. Further increasing the percentage of PEM-produced oxygen directly fed to the t-FR up to $22 \%$, the proposed layout performs better than the reference system also with respect to acidification, marine eutrophication, and photochemical ozone formation impact categories. Finally, when a 33\% of oxygen exploitation is considered, better performances than those of the reference system in all impact categories with the exception of depletion of energy carriers, minerals and metals, and carcinogenic impacts due to toxic pollutants are achieved. The environmental performances of the reference 
case with respect to these latter impact categories cannot be approached by the proposed system, unless alternative, more sustainable carriers were developed.

The LCA study has two main limitations. First, the study did not consider the decommissioning of the units in the Foreground system (Section 2.3); however, because the construction phase has minimal contributions to the environmental impacts (see Fig. 6), it is expected that the decommissioning also has minimal contributions. Second, the results could not be compared with literature data; this is because no similar studies, i.e. that combine a Chemical Looping Combustion with a Power-to-Methane system, could be found in the literature.

\section{CONCLUSIONS}

This work presented an innovative process layout that integrates Chemical Looping Combustion of solid fuels and a Power-to-Methane system, based on hydrogen production through water electrolysis by means of Polymer Electrolysis Membrane driven by electricity from renewable energies, to achieve a net power production with near-zero $\mathrm{CO}_{2}$ emissions while simultaneously producing methane. The core of the layout is a multiple interconnected fluidized bed system equipped with a two-stage fuel reactor, a riser used as Air Reactor, a cyclone, a L-valve return leg, and a loop-seal.

A coupled hydrodynamic and kinetic model was applied to evaluate the flue gas composition and flow rate, and the power production of the CLC system. The performance of the hydrogen production unit was evaluated considering data from commercially available units, while that of the methanation unit by developing a thermodynamic calculation method based on minimization of the free Gibbs energy. Both the technical and environmental performance of the system were investigated in the paper. Technical performance was assessed evaluating the thermal power generated by MFB and methanation units, the number of electrolysis 
1 cells required to produce hydrogen, $\mathrm{CH}_{4}$ flow rate, and energy conversion efficiency.

2 Environmental performance was evaluated using the Life Cycle Assessment (LCA) methodology.

The proposed system produces, with respect to $1 \mathrm{~kg} / \mathrm{h}$ of fuel fed, a net thermal power of $4.3 \mathrm{~kW} / \mathrm{s}$ and a high purity $\left(C_{C H 4}>95 \%\right)$ methane stream equal to $3.310^{-4} \mathrm{Nm}^{3} / \mathrm{h}$ with near-zero $\mathrm{CO}_{2}$ emissions (around $810^{-8} \mathrm{Nm}^{3} / \mathrm{h}$ ). By considering that only energy from renewable sources was fed to the hydrogen production unit, it was assessed the capability of the proposed process to be used as an energy storage system. The estimated electric energy storage efficiency equates $16 \%$.

The LCA study shows that production and disposal of the oxygen carrier used in the Chemical Looping Combustion reactor represents the largest source of the environmental impacts, with contributions ranging from $90 \%$ up to $\sim 100 \%$ in all the impact categories. The environmental performance of the system with respect to a reference system that includes the conventional pathways to generate electricity and produce methane thus strongly depends on the lifetime amount of oxygen carrier required. The comparison shows that the proposed layout is environmentally preferable to the reference system only with respect to climate change and ionizing radiations impacts. However, when $33 \%$ of PEM-produced oxygen is available to be fed to the Chemical Looping Combustion reactor, the proposed layout becomes environmentally preferable with respect to all environmental categories with the exception of depletion of minerals and metals, and energy carriers, and cancer human health effects.

Possible strategies to improve the environmental impacts should therefore focus on further reducing (to $\sim$, theoretically) the amount of oxygen carrier required and /or on developing alternative OC that are more environmentally sustainable. 


\section{REFERENCES}

[1] World Resources Institute. Climate Analysis Indicators Tool 2019.

[2] Eurostat. European Statistics 2017. http://ec.europa.eu/eurostat (accessed June 30, 2019).

[3] Götz M, Lefebvre J, Mörs F, McDaniel Koch A, Graf F, Bajohr S, et al. Renewable Power-to-Gas: A technological and economic review. Renew Energy 2016. https://doi.org/10.1016/j.renene.2015.07.066.

[4] Leung DYC, Caramanna G, Maroto-Valer MM. An overview of current status of carbon dioxide capture and storage technologies. Renew Sustain Energy Rev 2014. https://doi.org/10.1016/j.rser.2014.07.093.

[5] Russo ME, Bareschino P, Olivieri G, Chirone R, Salatino P, Marzocchella A. Modeling of slurry staged bubble column for biomimetic $\mathrm{CO}<\mathrm{inf}>2</ \mathrm{inf}>$ capture. Int J Greenh Gas Control 2016;47. https://doi.org/10.1016/j.ijggc.2016.01.045.

[6] Diglio G, Bareschino P, Mancusi E, Pepe F. Numerical assessment of the effects of carbon deposition and oxidation on chemical looping combustion in a packed-bed reactor. Chem Eng Sci 2017;160:85-95. https://doi.org/10.1016/j.ces.2016.11.020.

[7] Bareschino P, Solimene R, Chirone R, Salatino P. Gas and solid flow patterns in the loop-seal of a circulating fluidized bed. Powder Technol 2014;264:197-202. https://doi.org/10.1016/j.powtec.2014.05.036.

[8] Mattisson T, Lyngfelt A, Leion H. Chemical-looping with oxygen uncoupling for combustion of solid fuels. Int J Greenh Gas Control 2009. https://doi.org/10.1016/j.ijggc.2008.06.002.

[9] Gayán P, Adánez-Rubio I, Abad A, De Diego LF, García-Labiano F, Adánez J. Development of $\mathrm{Cu}$-based oxygen carriers for Chemical-Looping with Oxygen Uncoupling (CLOU) process. Fuel 2012. https://doi.org/10.1016/j.fuel.2012.01.021.

[10] Rönsch S, Schneider J, Matthischke S, Schlüter M, Götz M, Lefebvre J, et al. Review on methanation - From fundamentals to current projects. Fuel 2016;166:276-96. https://doi.org/10.1016/j.fuel.2015.10.111.

[11] Terna, Piano di Sviluppo 2020. 2020.

[12] ISO. Environmental Management - Life Cycle Assessment - Requirements and guidelines. EN ISO 14044:2006. 2006.

[13] ISO. Environmental Management - Life Cycle Assessment - Principles and Framework. EN ISO 14040:2006. 2006.

[14] Coppola A, Solimene R, Bareschino P, Salatino P. Mathematical modeling of a twostage fuel reactor for chemical looping combustion with oxygen uncoupling of solid fuels. Appl Energy 2015;157:449-61. https://doi.org/10.1016/j.apenergy.2015.04.052.

[15] Solsvik J, Haug-Warberg T, Jakobsen HA. Implementation of chemical reaction equilibrium by Gibbs and Helmholtz energies in tubular reactor models: Application to the steam-methane reforming process. Chem Eng Sci 2016. https://doi.org/10.1016/j.ces.2015.10.011.

[16] Linstrom PJ, Mallard WG. NIST Chemistry webBook, NIST Standard Reference Database Number 69. Natl Inst Stand Technol 2014. https://doi.org/citeulike-articleid:3211271.

[17] Perry RH, Green DW. Perry's Chemical Engineers' Handbook, 8th Edition. 2013. https://doi.org/10.1017/CBO9781107415324.004.

[18] Ferrero D, Lanzini A, Santarelli M, Leone P. A comparative assessment on hydrogen production from low- and high-temperature electrolysis. Int J Hydrogen Energy 2013;38:3523-36. https://doi.org/10.1016/j.ijhydene.2013.01.065.

[19] Clift R, Doig A, Finnveden G. The Application of Life Cycle Assessment to Integrated 
Solid Waste Management. Part 1 - Methodology. Process Saf Environ Prot 2000;78:279-87. https://doi.org/10.1205/095758200530790.

[20] Wernet G, Bauer C, Steubing B, Reinhard J, Moreno-Ruiz E, Weidema B. The ecoinvent database version 3 (part I): overview and methodology. Int J Life Cycle Assess 2016;21:1218-30. https://doi.org/10.1007/s11367-016-1087-8.

[21] Zhang X, Bauer C, Mutel CL, Volkart K. Life Cycle Assessment of Power-to-Gas: Approaches, system variations and their environmental implications. Appl Energy 2017;190:326-38. https://doi.org/10.1016/j.apenergy.2016.12.098.

[22] Mistry M, Gediga J, Boonzaier S. Life cycle assessment of nickel products. Int J Life Cycle Assess 2016;21:1559-72. https://doi.org/10.1007/s11367-016-1085-x.

[23] Thorne RJ, Bouman EA, Sundseth K, Aranda A, Czakiert T, Pacyna JM, et al. Environmental impacts of a chemical looping combustion power plant. Int J Greenh Gas Control 2019;86:101-11. https://doi.org/10.1016/j.ijggc.2019.04.011.

[24] Fazio S, Castellani V, Salasa S, Schau E, Secchi M, Zamporti L, et al. Supporting information to the characterisation factors of recommended EF Life Cycle Impact Assessment method. 2018.

[25] JRC. Product Environmental Footprint Category Rules Guidance. Version 6.3. 2018.

[26] Hauschild MZ, Rosenbaum RK, Olsen SI. Life Cycle Assessment: Theory and Practice. Springer International Publishing; 2017. https://doi.org/10.1007/978-3-31956475-3.

[27] Sala S, Cerutti AK, Pant R. Development of a weighting approach for the environmental footprint. Publ Off Eur Union Luxemb 2018.

[28] Diglio G, Bareschino P, Mancusi E, Pepe F, Montagnaro F, Hanak DP, et al. Feasibility of $\mathrm{CaO} / \mathrm{CuO} / \mathrm{NiO}$ sorption-enhanced steam methane reforming integrated with solid-oxide fuel cell for near-zero-CO2 emissions cogeneration system. Appl Energy 2018. https://doi.org/10.1016/j.apenergy.2018.08.118. 
1

2

\section{Captions for Tables}

Table 1 - Properties of considered fuel

Table 2. Environmental impact categories analysed

Table 3 - MFB-CLC model outputs

Table 4 - HP-PEM model outputs

Table 5 - Methanation units model outputs

\section{Captions for Figures}

Figure 1. - Conceptual scheme of the proposed process

Figure 2. - Schematic representation of the MFB system along with the indication of main geometric and operating variables.

Figure 3 - Simplified boundaries of the comparative analysis between the innovative process proposed in this study and the reference system. For simplicity, the diagram does not include the construction phase of the units in the Foreground system.

Figure 4-Gas molar fractions at the outlet of methanation unit as a function of the operating temperature at an operating pressure of 5 bar (solid lines), 20 bar (dotted lines), and 30 bar (dashed lines).

Figure 5 - Comparison between normalised environmental impacts of the proposed process layout and the reference system

Figure 6 - Hot-spot analysis of the proposed process layout. The label "Construction" includes construction of all units.

Figure 7. - Normalised environmental impacts of the reference system, the proposed process, and scenarios for PEM-produced oxygen exploitation. 